Fellow of the Royal Academy of Medicine of Ireland; President of the Royal College of Surgeons of Edinburgh from 1910 to 1912; a member of Edinburgh University Court; and a Manager of the Royal Infirmary. During the last War he established and conducted the Ophthalmic Department of the Second Scottish General Hospital, Edinburgh. He was appointed Honorary Surgeon Oculist in Scotland to H.M. King Edward VII, and to H.M. King George V, and in 1916 the honcur of Knighthood was conferred upon him. From 1922 to 1931 he was Member of Parliament (Conservative) for the Scottish Universities; at the end of which period he received the Honorary LL.D. of Edinburgh University.

Sir George Berry was a man of remarkable ability. Physically vigorous, he enjoyed outdoor sports-especially golf and angling. He was much interested in music and played the 'cello. He took a prominent part in relation to the Foundation of the Reid Chair of Music in the University of Edinburgh. His great interest in mathematics was abundantly shown in his text-book and in his contributions to this subject. He possessed a remarkable acquaintance with modern languages and especially with the less generally known Norse tongues, with which he had become familiar in early life. His brightness of mind, his scientific imagination, and high and varied attainments were fully recognised and highly valued by his colleagues, and he was much beloved by a wide circle of friends.

When he retired from a long life of high attainment and great activity, he resided at North Berwick, where he had built a house and layed out an excellent garden, in which he took great pleasure. He married in 1883, Agnes Jean, daughter of the late Sir William Muir, K.C.S.I., by whom he was predeceased; and is survived by three daughters.

With the passing of Sir George Berry only two of the original members of the Ophthalmological Society now remain, Sir Thomas Barlow and Sir Lindo Ferguson.

A. H. H. S.

\title{
THOMAS SNOWBALL
}

The late Mr. Thomas Snowball of Burnley was born in Huntly, Aberdeenshire, in 1873 and received his early education in that place. From there he proceeded to Aberdeen University where he graduated M.A. in 1892 and M.B., Ch.B. in 1897. Eventually deciding to study ophthalmology, he held the appointment of clinical assistant at "Moorfields" and subsequently went to Germany for further experience. He settled in practice in Burnley nearly forty years ago and had a long association with the Burnley Victoria Hospital, to which he was appointed Honorary Ophthalmic and Aural Surgeon in 1926 on the death of his partner Mr. Herbert 
Edmondson. He always took the greatest interest in this Hospital which has just completed a new block to house the eye and ear, nose and throat department. Apart from this main ophthalmic appointment he held many subsidiary posts in the district.

Mr. Snowball was a very good German scholar and frequently made précis of articles in that language for the British Journal of Ophthalmology. He translated Oeller's "Atlas of rare Ophthalmoscopic conditions" and collaborated in the translation of "Weckebach's Arhythmia of the Heart" which comprised much of the work of the late Sir James Mackenzie whom he knew well as a fellow practitioner in Burnley. He was also joint author of the work "On the relations between intra-ocular tension and the general blood pressure," which was published in the Royal London Ophthalmic Hospital Reports.

Snowball was a keen upholder of his native Scotland, was for many years the Local Secretary of the Burnley and District Graduates Association, and was also one of the founder Members of the Caledonian Society. He was also a keen golfer and was greatly interested in cricket-one of his daughters being an international player of this game.

The writer of this notice would like to pay tribute to Snowball's memory as a man. He was naturally of a retiring nature, but when one got to know him, his kindly disposition, genial humour and well informed conversation, endeared him to his friends and acquaintances. He was also held in high esteem for his professional attainments and was a man quite incapable of performing any action which he did not consider to be absolutely correct. For many years he was a regular attendant at scientific meetings in London, Oxford and at the North of England Ophthalmological Society, of which he was President in 1929, and he will be greatly missed by all who knew him.

\section{Sir John Parsons writes :-}

I first knew Thomas Snowball when I was doing research work in the physiological laboratory at University College, London. He had recently returned from studying in Germany, and readily agreed to help me in my work. He proved an invaluable assistant and became a staunch friend, whose loss I deeply deplore. His training at Aberdeen and Leipzig was followed by a period at Moorfields, so that he acquired a wider experience of ophthalmology than usual. $\mathrm{He}$ was always meticulously careful and methodical in his work, which, if not specially distinguished for originality or brilliance, was eminently reliable. The British Journal of Ophthalmology is indebted to him for his excellent reviews of German papers. 